\title{
TIEMPO DE CENIZA (1961), DE CARLOS MURCIANO: ENTRE EL COMPROMISO Y LA RENOVACIÓN DEL LENGUAJE EN UN POETA DE ARCOS DE LA FRONTERA
}

\author{
María Eugenia Álava Carrascal \\ Universidad Isabel I
}

Fecha de recepción: 30/04/2021

Fecha de aceptación: 17/06/2021

La memoria es un pozo. No. Sería.

Es. Era. Está. No estuvo nunca. Estaba.

(Este claro silencio, 1970: 27)

\section{Resumen}

No fue hasta 1983 cuando Carlos Murciano (Arcos de la Frontera, 1931) se dedicó exclusivamente a la literatura. Su trayectoria literaria es, sin embargo, muy amplia, aunque en este trabajo solo haremos referencia a la lírica. Acumula más de treinta títulos en verso, siendo el primero El alma repartida (1954) y el último Sonetos para ella (Ars Poética, 2018). En 1970 obtuvo el Premio Nacional de Poesía por Este claro silencio, siendo su máximo galardón. Participó en la fundación, junto a su hermano mayor Antonio, de la revista de poesía Alcaraván (1949), fruto de un grupo de amigos gaditanos que conformaron lo que con el tiempo se ha llamado «Escuela de Arcos de la Frontera». Con semejante trayectoria de galardones, de participación en la vida cultural española y de extensa obra poética, sorprende que esté al margen del canon de los poetas del medio siglo tradicionalmente generado a raíz de antologías con afán historicista. Quizás esa exclusión recalcitrante sea una condición compartida por varios poetas andaluces, como a menudo tuvieron que reivindicar desde antologías propias y orientadas hacia Andalucía como tema. Pero, fundamentalmente, su poesía es de corte tremendamente personalista y está atravesada de principio a fin por una tensión irresoluble entre el yo y los otros, entre el tiempo histórico y el tiempo estático de la conciencia y, como tal, es una poesía meditativa que escapa a las catalogaciones estancas y que a menudo sorprende por clara y otras veces por conceptista y esteticista en exceso. Presentaremos una breve trayectoria del recorrido de la obra de Murciano a través de las antologías para detenernos en Tiempo de ceniza (1961). El fin último del trabajo es determinar las claves estéticas de la poesía de Murciano y, en particular, del poemario seleccionado como ejemplo de esa tensión entre compromiso e introspección.

Palabras clave: Realismo histórico, poesía social, generación del sesenta, poesía novísima. 
Enclaves. Revista de Literatura, Música y Artes Escénicas, n.o 1, 2021, pp. 173-195. e-ISSN 2792-7350

María Eugenia Álava Carrascal, «Tiempo de ceniza (1961) de Carlos Murciano: entre el compromiso y la renovación del lenguaje en un poeta de Arcos de la Frontera», https://dx.doi.org/10.12795/enclaves.2021.i01.12

\title{
CARLOS MURCIANO'S TIEMPO DE CENIZA (1961): BETWEEN THE COMMITMENT AND THE RENEWAL OF LANGUAGE IN A POET FROM ARCOS DE LA FRONTERA
}

\begin{abstract}
It was not until 1983 when Carlos Murciano (Arcos de la Frontera, 1931) devoted himself exclusively to literature. His literary career is, however, very broad, although we will only refer to the lyrical work. The poet accumulates more than thirty titles in verse, the first being El alma repartida and the last Sonetos para ella, published in Ars Poética in 2018. In 1970 he won the National Poetry Prize for Este claro silencio, that was his highest award. He participated in the founding of the poetry magazine Alcaraván (1949), which was the result of a group of friends who formed the «School of Arcos de la Frontera». With such a track record of awards, participation in Spanish cultural life and extensive poetic work, it is surprising that Murciano is outside the canon of the poets of the midcentury traditionally generated because of anthologies with historicist zeal. Perhaps this recalcitrant exclusion is a condition shared by several Andalusian poets as they often had to claim from their own anthologies and oriented towards Andalusia as a theme. But, fundamentally, the poetry of Murciano is tremendously personalistic and is crossed from beginning to end by an irresolvable tension between the self and the others, between the historical time and the static time of the conscience and, as such, it is a meditative poetry that escapes to the watertight categorizations and that often surprises for being clear and other times for being conceptist and aestheticist in excess. We will present a brief trajectory of Murciano's work through the anthologies at first, and then we will dwell on Tiempo de ceniza (1961). The aim of the work is to determine the aesthetic keys of Murciano's poetry and, in particular, of the collection of poems selected as an example of this tension between commitment and introspection.
\end{abstract}

Keywords: Historical realism, Social poetry, Generation of the Sixties, Novisim poetry.

\section{Sumario}

1. Introducción

2. La poesía de Carlos Murciano en las antologías de los años 60-70 y una reflexión sobre los poetas andaluces en el canon poético del medio siglo .................................. 176

3. Algunas claves poéticas de un autor entre el realismo comprometido y la renovación del lenguaje a través de los poemas de Tiempo de ceniza (1961) ................................ 181

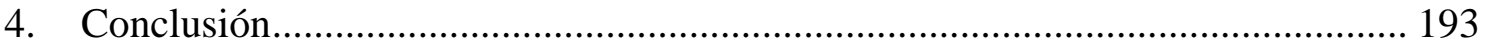

Agradecimientos y financiación................................................... 194

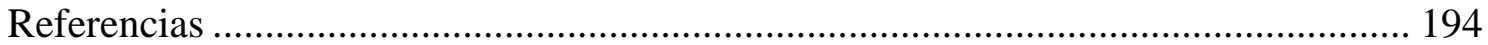

\section{Introducción}

Carlos Murciano González-Arias de Reyna nació en 1931 en Arcos de la Frontera y se trasladó después a Madrid. Dedicó sus esfuerzos laborales a la intendencia mercantil durante treinta años y no fue hasta 1987 cuando se dedicó exclusivamente a la literatura (López Azorín). Cabría mencionar que Murciano es también ensayista, traductor y crítico 
de música y arte en general. Su trayectoria literaria es sin embargo muy amplia y está traducida a más de diez idiomas, aunque en este trabajo solo haremos referencia a su trayectoria lírica hasta los años ochenta, dejando de lado los poemarios de los noventa y del nuevo siglo.

El poeta acumula más de treinta títulos en verso. El primero fue El alma repartida, en 1954, ${ }^{1}$ y el último Sonetos para ella, publicado en la editorial Ars Poética en 2018 y siendo fiel reflejo del profundo interés del autor por esa forma poética que fue la protagonista en más de una antología poética en torno a su obra, compilada por él mismo, y que fue, en sus propias palabras: «Lo primero que yo escribí en la vida» (Murciano apud. López Azorín, 1966, transcripción propia). En 1954 obtuvo el accésit al premio Adonais con Viento en la carne (1955); en 1970, el Premio Nacional de Poesía por Este claro silencio (1970). El primero fue el comienzo de una promesa y el segundo su galardón más importante hasta ahora. ${ }^{2}$ Antes habría conseguido también el premio Ciudad de Barcelona en 1962 por Un día más o menos (1963), el Ausias March por Los años y las sombras en 1966, el Boscán en ese mismo año por Libro de epitafios (1967) y el Ciudad de Palma en 1970 por Clave (1972).

Murciano participó en la fundación, junto a su hermano mayor Antonio, de la revista de poesía Alcaraván en 1949, que a pesar de sus 32 números publicados permaneció más bien en los márgenes culturales durante un periodo en que las revistas poéticas fueron más que prolijas, reflejo de la multitud de tendencias que en literatura se agolparon después de la Guerra de España. ${ }^{3}$ La revista era fruto de un grupo de amigos gaditanos que conformaron lo que con el tiempo se ha dado en llamar «Escuela de Arcos de la Frontera» (Hernández Guerrero) y que estaba capitaneado por Julio Mariscal, quien sí que estuvo incluido en la antología de Antonio Hernández de 1978, Una promoción desheredada. La poética del 50, como representante del grupo de poetas del medio siglo. ${ }^{4}$ El grupo llegó a crear un premio de poesía en 1953 (Hernández Guerrero) y una colección del mismo género en 1956 que abrió precisamente Poemas tristes a Madia de Murciano (Hernández Guerrero). ${ }^{5}$ Carlos Murciano participó con trabajos de ensayo en otras revistas de gran repercusión dentro de la península, como las dos dirigidas por José García Nieto, Poesía Española (1952-1977) y Poesía Hispánica (1971-1977), continuación de la anterior, acompañado también de su buen amigo José Gerardo Manrique de Lara.

Con semejante trayectoria de galardones, de participación en la vida cultural española y de extensa obra poética, sorprende entonces que Murciano esté al margen del canon de los poetas del medio siglo que tradicionalmente se ha generado a raíz de antologías de referencia con afán de historificar como la de Ángel Luis Prieto de Paula,

\footnotetext{
${ }^{1}$ A pesar de que el libro se publicase en la editorial Lírica Hispana de Connie Lobell de Caracas, fruto de un interés por el mundo hispanoamericano que siempre acompañó al poeta.

${ }^{2}$ Este claro silencio obtuvo en 1969 un accésit al premio Leopoldo Panero de poesía con un jurado conformado por Gregorio Marañón, director del Instituto de Cultura Hispánica, Hugo Lindo, Luis Rosales, Guillermo Díaz-Plaja, Torcuato Luca de Tena, José Hierro y José Rumeu de Armas como secretario. Se editó, por tanto, en el número 16 de la colección de poesía Leopoldo Panero de Ediciones Cultura Hispánica. En el año 2000, Carlos Murciano obtuvo el premio Internacional Atlántida por el conjunto de su obra.

${ }^{3}$ Remitimos al lector interesado al ya famosísimo trabajo de Rubio (1976) para más información sobre las revistas poéticas durante el franquismo.

${ }^{4}$ Julio Mariscal, Juan de Dios Ruiz Copete, Antonio Luis Baena y Cristóbal Romero, además de los dos hermanos Murciano, eran los principales integrantes del grupo.

${ }^{5}$ Los dos hermanos Murciano compilaron en 1958 la Antología de poetas de Arcos de la Frontera, donde incluían también su propia obra en ese esfuerzo por visibilizar a poetas que se situaron en la periferia de los cánones debido, principalmente, a su origen geográfico.
} 
Poetas españoles de los cincuenta. Estudio y antología (2002). Pero más sorprende que esté excluido también en trabajos que precisamente centraron parte de sus esfuerzos en reivindicar a los poetas tradicionalmente excluidos del canon como el de Luis Miguel García Jambrina, La promoción poética de los 50 (2007). Quizás esa exclusión recalcitrante de todas las nóminas sea una condición que, por otro lado, fue compartida por varios poetas andaluces, como a menudo tuvieron que reivindicar desde antologías propias y orientadas hacia Andalucía como tema en sí, sobre todo a partir de la década de los setenta, como veremos más adelante en este trabajo. Pero, probablemente, también una de las razones fundamentales sea la falta de adecuación de la obra de Murciano a la estética predominante del medio siglo poético en España, donde el «realismo histórico» de signo comprometido de los poetas en torno a Barcelona y de los enclaves matritenses, se alzó con las claves del éxito editorial de la mano, sobre todo, de José María Castellet en su antología-manifiesto Veinte años de poesía española (1960). Su poesía (1950-1988) fue recuperada por Plaza y Janés en $1989,{ }^{6}$ en un volumen antológico donde el autor incluía un poema inicial en forma de poética que rezaba:

[...] Escribo, sufriendo, de lo que vivo - y palpo-: emocionándome, de lo que viviré — intuyo-; gozando, de lo que viví —y añoro-.

Poesía, temblor humano del espíritu.

La clave está en saber encontrar a los demás buscándose a sí mismo [...] (Antología poética 7)

Porque, en efecto, la poesía de Carlos Murciano es de corte tremendamente personalista y está atravesada de principio a fin por una tensión irresoluble entre el yo y los otros, entre el tiempo histórico y el tiempo estático de la conciencia y, como tal, es una poesía meditativa que escapa a las catalogaciones estancas y que a menudo sorprende por clara y otras veces por conceptista y esteticista en exceso. El andalucismo es, además, un valor añadido que no es posible desligar de sus versos por voluntad explícita del poeta.

En las siguientes páginas presentaremos una breve trayectoria del recorrido de la obra de Murciano a través de las antologías de poesía andaluza de los años sesenta y setenta en un primer momento, para detenernos después en un libro concreto publicado en 1961: Tiempo de ceniza. El fin último del trabajo y de ambos apartados es determinar las claves estéticas de la poesía de Murciano y, en particular, del poemario seleccionado, entendido como punto de inflexión fundamental entre, y como ejemplo de, esa tensión entre compromiso e introspección que venimos defendiendo como poética general del autor gaditano. En último término, se trata de recuperar la obra del poeta y de reinscribirle, por medio de este modestísimo esfuerzo, en una tradición poética que, además, desde que se fijase el fin del realismo hacia 1963 en España, ha estado lejos de presentar límites claros ni estéticos, ni geográficos, ni generacionales en su historia de la literatura.

\section{La poesía de Carlos Murciano en las antologías de los años 60-70 y una reflexión sobre los poetas andaluces en el canon poético del medio siglo}

Carlos Murciano ha estado siempre al margen de las nóminas del canon peninsular del medio siglo por varias razones. La primera parece sin duda estética, como venimos planteando. Su poesía no puede contextualizarse plenamente en lo que José María Castellet denominó «realismo histórico» en Veinte años de poesía española (1960) y, por

\footnotetext{
${ }^{6}$ La primera edición de esa antología poética recuperaba su obra hasta 1972 y se publicó en 1973.
} 
lo tanto, no fue posible incluirlo tampoco en las nóminas canonizadoras posteriores que en torno a tales claves poéticas se consolidaron, fundamentalmente a raíz de los respectivos trabajos de Antonio Hernández y Juan García Hortelano en 1978.

Sin embargo, Murciano sí que apareció en algunas antologías del medio siglo y que, sobre todo a partir de la década de los setenta, se configuraron, en cada caso con diferentes fines, pero siempre con el andalucismo como bandera distintiva y principio regulador. Fue especialmente a partir de esa década cuando desde Andalucía se produjo un resurgimiento de corte nacionalista llamado a reivindicar la cultura de una comunidad que durante los años centrales del siglo XX había sido relegada a un segundo plano en favor de las órbitas madrileñas y barcelonesas, donde se habían aglutinado además las mayores posibilidades editoriales. ${ }^{7}$ Gracias a su aparición en esas antologías, precisamente, nos es posible descifrar algunas de las claves de su poesía, tal como se llevará a cabo en este apartado, a través de su participación en esas compilaciones de tan diferente objetivo estético entre sí en algunos de los casos. Y ello también nos permite constatar desde un primer momento ese posicionamiento al margen de las líneas poéticas principales del medio siglo en España y deducir algunas de sus razones fundamentales, que nos aventuramos ahora a adelantar: (1) la poesía del gaditano se situaba a caballo entre el compromiso de los años cincuenta y el esteticismo de los novísimos. Y, bidireccionalmente, (2) esa transición poética estaba influida por una impronta puramente andalucista que se puede percibir en esa suerte de simbolismo de luz crepuscular que reclamó siempre Concha Lagos desde las líneas de fuego de Cuadernos de Ágora y que, como veremos un poco más adelante, algunos críticos incluso reclamaron como punto de partida de la renovación de los novísimos ortodoxos en los setenta. La dificultad que había en España durante las décadas del cincuenta y sesenta para emprender iniciativas culturales fuera de los núcleos Barcelona-Madrid terminó de consolidar esa marginación de algunos poetas periféricos, primero de las líneas poéticas predominantes en la península, a veces por necesidad y a veces por voluntad propia, y después, lógicamente, de esas nóminas con voluntad de historificar que iban rescatando los nombres que hasta hoy más han permanecido en el imaginario colectivo.

La obra del poeta apareció recogida en una antología que precisamente la revista de Concha Lagos, Cuadernos de Ágora, realizó en 1961, en el número compuesto 53-56 de marzo-junio. Ello le proponía como candidato a poeta del grupo del medio siglo. La antología de la revista, confeccionada con motivo del cuarto centenario del nacimiento de Góngora, ${ }^{8}$ llevaba un prólogo escrito por Manuel Mantero donde se especificaba una «manera» andaluza (4) en los poetas más jóvenes que poblaban el panorama andaluz del medio siglo. Y, aunque el deseo claro de la nómina era incluir a esos poetas en el panorama general, «[t]odas las poesías son una» (Mantero 4), la distintiva marca de andalucismo de su poesía también se ponía de relieve insistentemente. De hecho, se recuperaba la poética gongorina recurriendo a los maestros del 27 y se les atribuía a estos jóvenes poetas, concediéndoles carácter de renovadores dentro del panorama del medio

\footnotetext{
${ }^{7}$ El volumen de Bayo (1991) es certero en la presentación de datos editoriales por zonas geográficas durante aquellas décadas.

${ }^{8}$ En la antología, cuyo consejo de redacción corrió a cargo de Gerardo Diego, José García Nieto, José Hierro y Jorge Campos, se daban cita los siguientes poetas: Manuel Alcántara, M. ${ }^{a}$ Victoria Atencia, Fausto Botello, Joaquín Caro Romero, Aquilino Duque, Julio Alfredo Egea, Medardo Fraile, M. ${ }^{a}$ de los Reyes Fuentes, Antonio Gala, José Carlos Gallardo, M. García Viñó, Luis de Góngora, Rafael Guillén, Luis Jiménez Martos, José G. Ladrón de Guevara, Concha Lagos, José G. Manrique de Lara, Manuel Mantero, Julio Mariscal, Carlos Murciano, Vicente Núñez, Fernando Quiñones y José M. ${ }^{a}$ Requena.
} 
Enclaves. Revista de Literatura, Música y Artes Escénicas, n. ' 1, 2021, pp. 173-195. e-ISSN 2792-7350

María Eugenia Álava Carrascal, «Tiempo de ceniza (1961) de Carlos Murciano: entre el compromiso y la renovación del lenguaje en un poeta de Arcos de la Frontera», https://dx.doi.org/10.12795/enclaves.2021.i01.12

\section{9:nclaves}

Revista de Literatura, Música y Artes Escénicas

siglo en España. El reclamo de una herencia de la tradición romántica andaluza, en clave fundamentalmente simbolista, se volvería a producir, como hemos dicho, en la década de los setenta, cuando Manuel Urbano reclamase para la estética novísima propuesta por Castellet en su antología de 1970 una tradición enraizada en el grupo Cántico, fundado en 1947. Lo desarrollamos un poco más adelante.

Otra de las compilaciones más relevantes para avanzar en la catalogación de la poesía del poeta gaditano fue la antología Poetas del sur de 1963, compilada por Luis Jiménez Martos en la colección Alcaraván, que reclamaba también esa impronta andalucista diferenciada del resto de la poesía española social-realista del momento (Hernández Guerrero 1357) con una marca distintiva en clave romántica y simbólica. En ella incluyó a los dos hermanos Murciano. Además, el propio Carlos Murciano preparó una antología con la misma intención última para el número 140-141 de la revista malagueña Caracola en el verano de 1964, donde figuraban Antonio Almeda, Antonio Luis Baena, Joaquín Caro Romero, José María Carrascal, Julio Alfredo Egea, Antonio Gala, Ángel García López, Manuel García Viñó, Rafael Guillén, Antonio Hernández, Luis Jiménez Martos, José G. Ladrón de Guevara, F. Martínez Llacer, Pedro Pozo Alejo, Fernando Quiñones, Manuel Ríos Ruiz, J. Ignacio Ruiz, Felipe Sordo Lamadrid, Rafael Soto Vergés y José María Velázquez (García Tejera et al. 34).

En todo caso, el hecho de que se le excluyera de esa nómina de Castellet de 1960 que fijó la etapa social-realista consolidó el lugar de Carlos Murciano como poeta de la periferia con respecto a esos núcleos de Barcelona-Madrid. De hecho, en Poetas andaluces de los años cincuenta. Estudio y antología, Murciano aparecía recogido, en base a parámetros fundamentalmente temporales, como parte de esa nómina de poetas del medio siglo de la que además otros muchos nombres de andaluces habían sido también apartados (Guzmán Simón 1402). Esa antología, de carácter revisionista, reafirmaba la idea de que, al menos por edad, Murciano podría haber formado parte de ese grupo poético de los cincuenta en el que la poesía realista de carácter comprometido fue la protagonista de acuerdo con las categorizaciones más tradicionales. La antología editada por María del Carmen García Tejera y José Antonio Hernández Guerrero en 2003 ponía de manifiesto que muchos poetas andaluces fueron excluidos de ese canon en los florilegios que en los setenta trataron de fijar los parámetros del social-realismo. Proponía también un componente andalucista como clave estética singular de los poetas que en ella se recogían. Y se podía percibir que esa estética se planteaba como parcial responsable de esa exclusión histórica de las nóminas canónicas: «Estamos en condiciones de abordar aspectos y matices que no siempre se han tenido en cuenta e, incluso, ésta es la ocasión para reparar ciertos inmerecidos olvidos» (García Tejera et al. 13). Pero hacía especial hincapié en el factor geográfico como motivo, casi logístico, de determinismo y consecuente exclusión del canon durante el franquismo: «A nuestro juicio, constituye un grave error aplicar los mismos criterios para definir al grupo de Barcelona, al de León, al de Galicia, o al de Andalucía. [...]» (García Tejera et al. 11). Concha Lagos, activista incansable de la estética de la poesía andaluza como un tono diferenciado de la del resto de la península, así lo habría defendido siempre desde su revista, ${ }^{9}$ tal y como hemos visto en el prólogo de Manuel Mantero a la antología que preparó su publicación periódica en 1961. Aunque en su caso primaron siempre los razonamientos estéticos, puesto que la

\footnotetext{
${ }^{9}$ Fundamentales para estudiar la trayectoria cultural de Concha Lagos en el medio siglo son los muchos trabajos de Blas Sánchez Dueñas.
} 
falta de distancia temporal complicaba el razonamiento geográfico que hoy en día se tienen en cuenta en más o menos medida en los estudios filológicos.

La cuarta antología donde el poeta se dio cita con otros nombres de andaluces fue el ya mencionado trabajo compilado por Manuel Urbano en 1976, Andalucía en el testimonio de sus poetas, que, además de otorgarle de nuevo ese carácter intachable de cantador a su patria, añadía una nueva dimensión de esteticismo renovador a su poesía. Porque la crestomatía de poesía de Urbano se erigía también como una suerte de respuesta ante la de Nueve novísimos poetas españoles (1970) de José María Castellet, que había intentado promover esta vez a una nueva generación de poetas jóvenes con una hoja de ruta aparentemente común en torno a la renovación estética del lenguaje, pero que realmente el crítico dividía en dos líneas fundamentales: una «ilógica razonada» y otra «simbolista» (Lanz, Nuevos y novísimos poetas... 40). Frente a eso, la introducción del trabajo de Urbano sostenía que en los poetas andaluces jóvenes se podía observar también una estética renovadora en materia de lenguaje, pero no repleta de los efectismos que primaban en la poesía de los «ilógicos razonados» de la nómina del barcelonés, sino más bien en la línea del simbolismo y sin renunciar a un marcado componente de compromiso con la patria: «Trayectoria, en la que se puede apreciar un desencanto mágico y misterioso, contenido a la vez que desgarrado y elegante, $[\ldots]$ en el que tendrían su entrada lo hondo y la pena; junto a ello, siempre, una armonía, un sentido sobrio del gusto y la belleza con tintineos sensuales, sin ocultar una íntima satisfacción» (17). ${ }^{10} \mathrm{Y}$ es que subrayaba, además, que la poética de algunos de los antologados por Castellet enraizaba precisamente con el ya mencionado grupo Cántico y que, por tanto, no suponía ninguna novedad real, e incluso era heredera precisamente del sentir simbolista de la poesía andaluza tradicional:

Resulta curioso José María Castellet y sus «nueve novísimos», a las alturas de los setenta, con una poética realizada veintitantos años antes por García Baena y Ricardo Molina, a quienes ahora se les está «descubriendo». (22)

Urbano justificaba así que ese sentir novísimo planteado como algo rupturista en los setenta era, sin embargo, inherente a la poesía de los andaluces, heredado de una tradición de larga solera. Más adelante, Degeneración del 70 (Antología de poetas heterodoxos andaluces) sería, en la misma línea, el intento de Francisco Gálvez de 1978 de diseñar una línea poética diferente de aquella promovida por la nómina castelletiana que se impuso en 1970, a través de un grupo de novísimos heterodoxos, también jóvenes andaluces (Hernández Guerrero 1367).

Por último, Carlos Murciano fue incluido en la antología Cuarenta y cinco poetas andaluces que realizó Luis Jiménez Martos para Tránsito. Revista de poesía en enerofebrero de 1982, la cual se puede entender como otra reivindicación totalizadora de corte andalucista frente a una marginación geográfica histórica, ${ }^{11}$ además de una reivindicación en clave estética, como venimos comentando. Incluso podríamos considerar que la poesía de «La otra sentimentalidad» que en 1983 promovieron desde Granada Luis García Montero, Javier Egea y Álvaro Salvador fue el último estertor de un combate

\footnotetext{
${ }^{10}$ Más representativo en este sentido fue, sin embargo, el trabajo de Urbano (1980), donde incluía una nómina de poetas más jóvenes entre cuya obra la intención de renovación del lenguaje era ya una completa evidencia.

${ }^{11}$ El espléndido trabajo de Fernando Guzmán Simón (2008) es inestimable para acercarse a una panorámica amplísima sobre las revistas y las antologías consagradas a la poesía andaluza en el siglo XX.
} 

Frontera», https://dx.doi.org/10.12795/enclaves.2021.i01.12

reivindicativo frente a una marginación mantenida de la literatura andaluza respecto de los cánones estatales (Lanz apud. Lanz y Vara Ferrero 210). Las antologías que desde los setenta en adelante asistieron, como hemos dicho, a ese resurgir de una poesía marginada forzosamente durante las décadas anteriores coincidían precisamente con el momento del fin de ese aislamiento geográfico en pequeñas zonas con riqueza desigual, que había sido una de las grandes consecuencias de la Guerra de España y hasta la Transición. Sus compiladores optaron por defender la nacionalidad andaluza en la poesía en claves estéticas distintivas, más que en promover un sentimiento de rencor ramplón por una exclusión geográfica; porque además ese factor comenzaba a perder el sentido a consecuencia de la eliminación de límites que desde el Plan de Estabilización se habían ido venciendo poco a poco. ${ }^{12}$ Sin embargo, ello no debe oscurecer el hecho de que durante los años centrales del siglo pasado esas limitaciones geográficas eran determinantes para la cultura en varios sentidos y, por tanto, merece la pena tenerlas en cuenta desde la perspectiva actual porque pueden aportar claves interesantes para comprender las diferencias entre los muchos grupos de poetas del medio siglo y los sesenta, y son inestimables para el análisis filológico de ese periodo y la comprensión de cómo se construyeron los cánones que aun hoy guían nuestras investigaciones. ${ }^{13}$

En este trabajo hemos optado ahora por una opción de análisis también fundamentalmente estética y descriptiva, por sus modestísimas pretensiones y la imposibilidad de acometer un estudio sociodemográfico al alimón que arroje más luz al problema de la geografía. Además, Carlos Murciano no vivió siempre en Arcos de la Frontera, por lo que en su caso particular, a pesar de que su poesía esté muy influida por la impronta andalucista, no sería demasiado determinante. Evaluaremos entonces algunas de las claves poéticas del gaditano a través de su poemario Tiempo de ceniza, considerándolo libro clave en la evolución de su poesía. Y, para ese planteamiento, la inclusión de Murciano en el trabajo de Manuel Urbano de 1976 es la más relevante, pues nos permite plantear que su obra estaba ligada a esa renovación estética del lenguaje que estaba ocurriendo en España desde mediados de la década de los sesenta y a la que algunos críticos han dado en referirse con el marbete de «generación del sesenta», ${ }^{14}$ a medio camino entre los poetas realistas del grupo del cincuenta y ese cajón de sastre en que se constituyeron los genéricamente denominados novísimos. Efectivamente, esto no es

\footnotetext{
${ }^{12}$ Aunque en la introducción de Manuel Urbano aún se podían leer frases como: «De los poetas andaluces en toda España ya esperan siempre lo peor, no nos hagamos ilusiones» (9).

${ }^{13}$ La Teoría de los Polisistemas de Itamar Even-Zohar (1990) es fundamental para entender la importancia de las redes de contacto y los núcleos de escritores como elementos esenciales para la configuración de un canon o de una historia literaria.

${ }^{14}$ No es fácil, sin embargo, determinar qué nombres pueden incluirse en esa generación acuñada como tal, por ejemplo, por Luis Miguel García Jambrina en su trabajo antológico sobre la poesía del medio siglo de 2007. Tampoco es fácil determinar cuáles son los factores aglutinantes de la poesía de los autores en ella incluidos, porque los diferentes críticos que se han referido a esa «generación del sesenta» no coinciden en las nóminas propuestas. Así, por ejemplo, García Jambrina incluía en su grupo a Miguel Fernández, Ángel García López, Diego Jesús Jiménez, Joaquín Caro Romero, Joaquín Benito de Lucas, Manuel Ríos Ruiz, Antonio Hernández, Jesús Hilario Tundidor, Carlos Álvarez Cruz, Félix Grande y Rafael Soto Vergés ( $\mathrm{La}$ promoción poética ... 25-26). Pero, mucho antes que él, José Olivio Jiménez había definido también una «generación del sesenta» en Diez años de poesía española (1960-1970), de 1972, incluyendo a un grupo de poetas diferente, cuyos trabajos contaban con cotas menores de «neobarroquismo» que algunos de los de García Jambrina. Miguel García Posada también señalaría explícitamente una «promoción del 60» en su trabajo antológico de 1979, 40 años de poesía española, de «voluntad didáctica» (37). En su caso, la organizaba esencialmente en torno a los nombres de Ángel González, Jaime Gil de Biedma, Claudio Rodríguez y José Ángel Valente.
} 
demasiado sorpresivo si reflexionamos sobre el devenir lógico de la obra del autor gaditano, puesto que se desarrolló también ampliamente durante la década del setenta y, lógicamente, las participaciones que se iban incluyendo en cada antología suponían novedades con respecto a las anteriores y, por consiguiente, una evolución necesaria en la trayectoria vital y poética del autor. ${ }^{15}$ Sin embargo, sí que es determinante para la identificación de claves estéticas que estaban ya presentes en sus poemarios anteriores y es precisamente esa, junto al paradigma geográfico, la razón que sosteníamos como fundamental al inicio para esa marginación de los cánones de poetas que se fueron adscribiendo a las antologías al realismo social del medio siglo después del fin de esa tendencia. Cerramos así el círculo de planteamientos suscitados hasta aquí y pasamos ahora al análisis de la poesía de Carlos Murciano.

\section{Algunas claves poéticas de un autor entre el realismo comprometido y la renovación del lenguaje a través de los poemas de Tiempo de ceniza (1961)}

La Isla de los Ratones fue el sello editorial de la revista del mismo nombre que en Santander comenzó a editar Manuel Arce junto a Joaquín y Gonzalo Bedia en 1948, recogiendo el testigo de Proel. El editor también contaba con la galería de arte y librería Sur en la misma ciudad. En Los papeles de una vida recobrada (2010), Arce narra a través de documentos personales la difícil situación en que se encontraba su revista durante la década de los sesenta, debido fundamentalmente a su activismo antifranquista. Llama la atención un pasaje que el editor cuenta en torno a los sucesos acaecidos después de que firmara la carta de los intelectuales en contra de las detenciones de los mineros asturianos en octubre de 1963:

La respuesta de los sectores más reaccionarios de la sociedad franquista no se hizo esperar. Pero sobre todo en mi caso: era el único firmante de Santander. [...] La alarma de la insensatez solo sonó cuando [...] en el correo, me llegaron los dos primeros anónimos: «Comunista, socialista, anarquista, rojo indecente, castrista. ¡Intelectual! Estás fichado, ten cuidado con lo que firmas». (596)

El fragmento es también ilustrativo respecto a la situación política que el sello editorial de su revista hubo de atravesar en esa década con respecto de las instituciones del segundo franquismo. Ello nos permite extrapolar qué tipo de obras tenía especial interés en editar. Tiempo de ceniza no fue, en ese sentido, ninguna excepción, ${ }^{16}$ y sus veintinueve poemas conformaron el número 14 de la colección «Poetas de Hoy». Manuel López Azorín definió el poemario en 1996, en una Tertulia de Autor de Canal Norte TV, que estaba prevista en un primer momento para ser presentada por José Hierro, como sigue: «un tiempo de pérdida, de cansancios y de búsquedas; también de búsquedas» (López Azorín, 1966, transcripción propia). Acepciones todas que permite comprender a la perfección por qué podemos considerarlo precisamente como un punto de inflexión en la trayectoria de su autor.

El primer rasgo que hay que poner de manifiesto cuando nos acercamos a la obra del gaditano es su andalucismo. Tiempo de ceniza fue escrito entre 1956 y 1958, y ya para ese entonces la trayectoria poética de Murciano estaba claramente influida por ese rasgo

\footnotetext{
${ }^{15}$ Los poemas incluidos en la antología de 2003 son la más representativa en este sentido por supuesto.

${ }^{16}$ La colección «Poetas de Hoy», donde apareció el libro de Murciano, editó setenta y tres obras entre 1949 y 1986.
} 
desde su primer trabajo de $1954 .{ }^{17}$ En El alma repartida (1954), en efecto, poemas como «El labrador» ${ }^{18} \mathrm{o}$ «Los segadores» hacen referencia implícita al paisaje de Arcos de la Frontera, poniendo de manifiesto la belleza de los campos que rodean la localidad dentro del grito de desesperación que ese poemario aún conlleva como parte integrante de la estética más comprometida de los poetas clásicos del medio siglo: «Sobre la paz del campo, / sobre ese vaho azul que a tierra sabe, / el labrador se yergue cada día.» (Antología poética 20). Quizás el ejemplo más significativo de esa pasión por la tierra se encuentre en la segunda parte de Este claro silencio (1970), titulada «Sierra de Cádiz», cuyo paratexto inicial, además, está en forma de versos de Antonio Machado: «En estos campos de la tierra mía...» (Machado apud. Murciano, Antología poética 167). Reseñable en ese

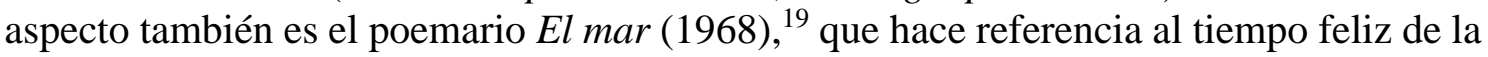
niñez en el mar de Cádiz a través de un cuadro de inspiración marítima del salón de su vivienda, siguiendo además así una de las temáticas más habitualmente compartidas por los poetas del medio siglo: la de la niñez como tiempo perdido durante la Guerra de España (García Hortelano 29) ${ }^{20}$ y acompañada de esa impronta nacionalista que venimos comentando:

En ti morían mis caminos, se deshacía mi desesperanza; por ti, mar de aquel cuadro inolvidable en el rincón más mío de la sala, por ti, mar de mi sed, y por aquella caracola de nácar que sobre el mármol rubio repetía su son, su sonrisa rizada, tuvo, mar de mis sueños, mar de verdad mi infancia. (9)

Hay también un poema titulado «Los viejos amigos» en Los años y las sombras (1966) que alude a la juventud del poeta en Cádiz con nostalgia y cariño: «[...] Con vosotros / encallecí mis manos intentando / abastecer la tolva a paletadas / de orujo, troceando el duro tronco / a golpes de hacha [...]» (21). No se puede dejar de mencionar tampoco el poema «Gitanillo cantando» ${ }^{21}$ de Clave (1972) que, en un estilo mucho más ya cercano al culturalismo y al esteticismo del lenguaje de que nos ocuparemos más adelante en este apartado, mantenía esa preocupación por la patria de procedencia, haciendo del tema una constante en la obra de Murciano:

\footnotetext{
${ }^{17}$ Una gran parte de sus primeros poemas fueron escritos entre 1954 y 1956, mostrando un proceso de escritura muy prolijo durante aquellos dos años, a pesar de que las publicaciones de algunos de los libros que terminaron por configurar aquellos versos fueran posteriores. Ello da cuenta también de una capacidad evolutiva muy grande en un poeta de intensa actividad cuya capacidad de mutación poética es manifiesta, como vemos a través de la evaluación de varios de los libros tal y como finalmente fueron publicados.

${ }^{18}$ Fue incluido en la sección «El campo» de la antología de 1976 de Manuel Urbano, Andalucía en el testimonio de sus poetas, así como «Los segadores».

${ }^{19}$ Fue premio Virgen del Carmen en 1968 y publicado entonces, aunque había sido escrito en 1958.

20 «[...] Evocación de un tiempo feliz, de los asombros e inocencias de la infancia, de la madre, de los juegos y de las melancolías, de la iniciación erótica, nostalgia del paraíso o recuerdo del horror, son algunas de las variantes que acompañan a la constante reconstrucción de lo imposible. [...]» (García Hortelano 29).

${ }^{21}$ Fue incluido en la sección «Los gitanos» de la antología de 1976 de Manuel Urbano, Andalucía en el testimonio de sus poetas.
} 
Enclaves. Revista de Literatura, Música y Artes Escénicas, n. ${ }^{\circ}$ 1, 2021, pp. 173-195. e-ISSN 2792-7350

María Eugenia Álava Carrascal, «Tiempo de ceniza (1961) de Carlos Murciano: entre el compromiso y la renovación del lenguaje en un poeta de Arcos de la Frontera», https://dx.doi.org/10.12795/enclaves.2021.i01.12

[...] Y una guitarra que no pulsa nadie, rompe, raja, rasguea, reverente, retumba en el tambor de la tormenta y echa a rodar por dentro del corazón [...] (Antología poética 190) $)^{22}$

Relevante también es constatar que el propio título de uno de sus poemarios más esteticistas en su caso, Meditación en Socar (1982), es un tributo a su pueblo natal, porque «Socar son las letras de Arcos al revés» (Murciano apud. López Azorín, 1966, transcripción propia). En Tiempo de ceniza, en particular en la tercera sección, titulada «País donde seremos», destaca por ejemplo un poema de nombre «El ave», donde la bella descripción del ave que vuela sobre la tierra retrotrae decididamente a la fauna que Murciano describe en su libro de 1982 sobre Arcos de la Frontera: «El silencio no es oro, sino tierra. / A ras de tierra, de silencio, cruza / un ave extraña: si invisible en el vuelo / y vedado su canto, tiene forma / y en su forma pervive; brisa o pluma, / frágil esguince o ráfaga celeste, / la soledad [...]» (Tiempo de ceniza 60 ).

Como ya venimos proponiendo, el compromiso social, de corte realista, es el segundo rasgo fundamental de la primera poesía de Murciano. Y es también el que más cambiará a lo largo de los años para dejar paso a un compromiso de corte más introspectivo, como veremos más adelante. Es, en definitiva, una de sus claves más importantes en materia de transformación poética. El compromiso de carácter más beligerante aún está muy presente en el poemario de 1961, como también lo habría estado en los poemarios anteriores a esta fecha, que podemos entender ya como una suerte de punto de inflexión. De hecho, lo estaba mucho más en los libros anteriores.

El poeta Miguel García Posada definía una de las claves de evolución de la «promoción del 60» con respecto a los poetas tradicionalmente canonizados en las nóminas en el medio siglo ${ }^{23}$ en su ya citada antología de 1979, de voluntad didáctica, en los siguientes términos: «Esta promoción puede ser caracterizada por la voluntad en ella existente de escribir una poesía crítica, moral, pero sin las limitaciones de la poesía social, aunque no dejara de pagar su tributo al género aún dominante [...].» (29). Y eso es lo que ocurre precisamente en Tiempo de ceniza con respecto a, por ejemplo, lo que podíamos ver en Viento en la carne (1955): «La tierra hablaba con rumor de sangre / y una ausencia de ríos sin espejos / iba arrastrando un pálpito de polvo / — nada era nada - hacia el misterio» (Murciano, Antología poética 34). Efectivamente, en el poemario de 1961 el compromiso viene reflejado ya de una manera mucho más sutil y menos beligerante, bien

\footnotetext{
${ }^{22}$ Cabe mencionar en este punto que Murciano realizó también un volumen de carácter divulgativo sobre Arcos de la Frontera en 1982, editado por Everest y cuya dirección artística corrió a cargo de Emilio Marcos Vallaure, que fue premio Turismo Everest 1973, y donde, entre otros muchos preciosismos sobre la historia de la región, se podían leer cosas como: «Pues bien, en este grato ir y venir a lo largo y ancho de la española geografía, recalamos hoy en un pueblo distinto: un pueblo alto, de siglos, torreado, color de pan: la corteza, dorada; la miga — el corazón — blanca; un pueblo ceñido de río susurrante, de huertas olorosas, regadas al atardecer [...]; pueblo frontero entre la realidad y el sueño [...], pueblo clavado en mitad de una clara provincia — Cádiz, plateada y salina — en mitad de una clara región —Andalucía —, en mitad del recuerdo; pueblo con nombre inolvidable: Arcos de la Frontera. Piedra y estrella. Alborozo y silencio» (Arcos de la Frontera 8-9).

${ }^{23}$ García Posada incluye, por ejemplo, a José Ángel Valente en ambas generaciones, del cincuenta y del sesenta, lo cual complica la definición estética del marbete propuesto para denominar a los poetas cuya obra parece suponer una evolución sobre las de los años anteriores. Y a Jaime Gil de Biedma, por su parte, le relega exclusivamente a la promoción del 60, lo cual podría ser discutible, al menos a efectos de terminología, teniendo en cuenta que las antologías que se han referido al periodo del medio siglo siempre incluyen al poeta dentro de sus nóminas.
} 
por una opción personal orientada más al compromiso moral ${ }^{24}$ que a la denuncia puramente beligerante contra el régimen, bien por una impronta poética de carácter más simbolista y menos narrativo compartida por los poetas andaluces, o simplemente como consecuencia de una evolución poética compartida por casi todos los autores del momento, fruto de la sutil relajación de las medidas de represión de la dictadura a partir de los planes de desarrollo de 1959 y su epónimo Laureano López Rodó.

Así, desde el primer poema de la primera sección, «Desde este lado», titulado «De verdad», el poeta se pregunta por un tiempo generacional perdido en los vaivenes de la posguerra. Pero lo hace de manera parcialmente surrealista, puesto que no emplea los típicos recursos pragmáticos de la lírica de preguntar en apóstrofe a un lector imaginado o incluso a los compañeros de generación, sino que lo hace con los muebles de su casa, de quienes además obtiene respuesta:

De verdad. No encuentro nada.

Todo lo tengo perdido.

Abro el armario. Pregunto

a los muebles: «¿Lo habéis visto?»

mudos, responden: «¿El qué?»

Y yo, cansado: «Lo mismo

me da. Solo quiero algo

de lo que tuve, algo limpio,

algo bueno, algo con alas,

algo blanco...» [...] (Tiempo de ceniza 17$)$

Más adelante, en el poema «Sísifo», el poeta se autoevalúa en una suerte de correlato objetivo con el protagonista del mito camusiano, poniendo de manifiesto la inutilidad de lo belicoso en medio de un clima ya de por sí agobiante: «Bajo la piel me palpo lo que soy, / lo que seré: mi propia calavera, / mi nada, mi mentira verdadera, / mi mañana colgando de mi hoy» (27). De nuevo, la denuncia no es tan beligerante y el poeta se vale de recursos pragmáticos, como es el correlato objetivo, precisamente para distanciarse del autobiografismo y trasladar una denuncia de carácter más sutil (Pérez Parejo 384), pero a la vez asumida desde una responsabilidad individual. Además, esto le imprime en una tradición de creciente modernización y cierta ironía en la que estaban sumidos también algunos de los poetas más jóvenes del medio siglo, especialmente los barceloneses en torno a la revista Laye, con respecto a sus mayores de la primera promoción de posguerra (Prieto de Paula 62). En último término, podemos observar también una pérdida de narratividad en el poemario más orientada hacia un simbolismo creciente, heredado, como decimos de esa marcada impronta andalucista, con respecto a los libros anteriores.

Los versos citados del anterior poema, «Sísifo», nos redirigen precisamente hacia la tercera gran preocupación en la poesía del autor gaditano. Jorge Murciano Maínez pone de manifiesto en su tesis doctoral que el historicismo y la concepción cambiante del tiempo en la obra de Murciano es una de las claves fundamentales. Y ello está en estrecha relación con la dimensión anterior, porque ya sabemos que los poetas comprometidos del medio siglo estaban imbuidos de un realismo precisamente «histórico», que fue además

\footnotetext{
${ }^{24}$ De confesionalidad profundamente católica, como veremos también claramente reflejado en algunos poemas de Tiempo de ceniza. Carlos Murciano, además, hizo crítica de poesía en el diario Ya, hasta bien entrada la década de los ochenta.
} 
Enclaves. Revista de Literatura, Música y Artes Escénicas, n. ' 1, 2021, pp. 173-195. e-ISSN 2792-7350

María Eugenia Álava Carrascal, «Tiempo de ceniza (1961) de Carlos Murciano: entre el compromiso y la renovación del lenguaje en un poeta de Arcos de la Frontera», https://dx.doi.org/10.12795/enclaves.2021.i01.12

\section{9:nclaves}

Revista de Literatura, Música y Artes Escénicas

una de las dimensiones principales responsables de que para la década de los setenta su poesía se considerase injustamente «envejecida» (García Posada 29) en muchos estudios de literatura española. José María Castellet había descrito ese marbete de «realismo histórico» en el prólogo a la primera edición de su antología de 1960 precisamente en los siguientes términos:

En todo caso se diría que la poesía que escriben hoy muchos de esos jóvenes poetas es el preludio de lo que podría ser un realismo histórico, que se refiriera no solo a un pasado más o menos próximo y a un presente que se ofrece ambiguo por la misma fuerza de las circunstancias, sino que también se proyectara sobre un futuro que hoy no se vislumbra con claridad aún. (104)

Definición que era, sin embargo, bastante clarificadora respecto a las posibilidades de aquellos poetas que se sumaron a una tendencia que en realidad no se agotaba tan rápido, aunque muchas veces se le haya acusado de tal caducidad, sino que podía configurarse también como una suerte de preludio, como una premonición que efectivamente ocurrió muy pronto, de manos de la «poesía dialéctica» que promovieron los poetas leoneses del Equipo Claraboya (1963-1968): Agustín Delgado, Luis Mateo Díez, Ángel Fierro y José Antonio Llamas. Pero lo que es evidente en la obra de muchos poetas como Claudio Rodríguez o Rafael Soto Vergés es que ese historicismo más marcadamente dependiente de la realidad extratextual que caracterizaba a la mayor parte de la poesía de los años cincuenta fue tornándose más bien intrahistórico, personal, a veces irónico, en una búsqueda de la historia vital como conciencia vivida, como había ocurrido en los planteamientos poéticos y filosóficos del último Antonio Machado, a los que todos esos poetas pagaban indiscutible tributo: «Justamente enorgullecido de su memoria llega el hombre a pensar que es, precisamente, lo pasado aquello que no pasa, porque los hechos cósmicos, cualquiera que sea su naturaleza, quedan solidificados e inmutables en el fluir de nuestra conciencia, al pasar de la percepción al recuerdo» (Machado 38-39).

Murciano Maínez ilustra las tipologías del tiempo en la poesía de Carlos Murciano en base a tres poemarios de su obra ulterior dispersos entre las décadas de los setenta y los ochenta: Este claro silencio (1970), Yerba y olvido (1977), Del tiempo y soledad (1978), Meditación en Socar (1982) e Historias de otra edad (1983) (Murciano Maínez). La evolución del tiempo histórico hacia el intrahistórico es uno de los elementos fundamentales que se puede deducir de la poesía del gaditano. Así, en Este claro silencio, como explica Murciano Maínez, comenzaría ya esa traslación hacia el terreno del interior, del tiempo como conciencia, de lo que finalmente se convertirá en tiempo infinito, aunque aún se encuentra enraizado en el terreno de lo palpable, de lo finito, de lo que ocurre en el aquí y ahora. Dice Murciano Maínez que en algunos poemas del libro el poeta «revive desde la inmediatez realista todo cuanto su mirada alcanza, cuanto su tacto va descubriendo al hilo de los elementos que lo rodean» (Murciano Maínez 58); y en otros ya, sin embargo, «esta misma conciencia cognitiva del sujeto poético pareciera traducirse en olvido; es decir, la experiencia vital será, a la postre, tiempo herido, tiempo en blanco, [...]» (Murciano Maínez 62).

Un día más o menos (1963) podría considerarse el máximo exponente del historicismo realista centrado en lo extratextual, porque los poemas no tienen, por ejemplo, más título que el día en que se escribieron, «a modo de diario» (Murciano apud. López Azorín, 1996, transcripción propia). También Estas cartas que escribo (1966) estaría en una línea similar. Historias de otra edad sería el culmen de un tiempo 
Enclaves. Revista de Literatura, Música y Artes Escénicas, n.o 1, 2021, pp. 173-195. e-ISSN 2792-7350

María Eugenia Álava Carrascal, «Tiempo de ceniza (1961) de Carlos Murciano: entre el compromiso y la renovación del lenguaje en un poeta de Arcos de la Frontera», https://dx.doi.org/10.12795/enclaves.2021.i01.12

fantástico, «iinfinito?» (Murciano Maínez 268), que además ya se había planteado también en la vida de los silfos de Cuando da el corazón la media noche $(1958)^{25} \mathrm{y}$, precisamente, en la última estrofa del poema introductorio de Tiempo de ceniza: «Eternidad, ¡qué breve / entreacto de la Vida! / Detened este tiempo: / ¡mi tiempo de ceniza!» (14). Así, en el caso de ese poemario que ahora nos ocupa nos encontramos entre dos aguas entre la concepción del tiempo como historia común de un pueblo y como intrahistoria, primero porque la preocupación por la dimensión temporal se refleja muy claramente desde el título y segundo en tanto que el símbolo de la ceniza se convertirá, además, a partir de este libro, en una metáfora de continua aparición en la obra del gaditano. Y se resignificará siempre en torno al problema tiempo; primero como tiempo presente y luego como memoria. Así, en este libro de 1961, el tiempo que discurre, el del presente, es la ceniza misma, un tiempo que al poeta se le escapa entre las manos e incluso llega a «Donde el poeta habla consigo mismo de la vaguedad del tiempo», al recapitular sobre las muchas concesiones que ya ha hecho:

\section{HASTA MAÑANA}

Por hoy ya se acabó lo que se daba. Aunque poco se daba, ciertamente un puñado de sueños y una frente que ya no está siquiera donde estaba.

Ayer estuvo aquí, rotunda aljaba conteniendo una fecha solamente, una flecha, mejor, que de repente sin que la disparasen se clavaba.

El corazón no dura lo que dura el hueso. Dura igual que la alegría y ésta, apenas nacida, se nos muere.

Igual que el hueso dura la amargura. En fin, mañana ya será otro día.

Hasta mañana, Dios, si el tiempo quiere. (44)

Aunque, poco a poco, irá convirtiéndose en el espejo donde el hombre puede mirarse a sí mismo también como tiempo transcurrido ${ }^{26}$ en el último poema del libro:

\section{EL TRIBUTO}

Con esta misma tierra que ahora yace náufraga de su propio helor, La Mano vino a formar - aún ignoraba el tiempo el lívido llover de la cenizacuerpos esbeltos, torres de hermosura [...] Pero el hombre no supo, no podía

\footnotetext{
25 También el subtítulo de la antología de sonetos El revés del espejo (1972), «(sonetos mágicos y corrientes)», recuerda a esa estética de lo fantástico.

${ }^{26}$ Recurriendo de nuevo a esa Fe católica que mencionábamos páginas atrás.
} 
Enclaves. Revista de Literatura, Música y Artes Escénicas, n. o 1, 2021, pp. 173-195. e-ISSN 2792-7350

María Eugenia Álava Carrascal, «Tiempo de ceniza (1961) de Carlos Murciano: Frontera», https://dx.doi.org/10.12795/enclaves.2021.i01.12

saber. Y, apenas hecho, rompió el vaso.

La Mano se contrajo dolorida,

quemada de su fuego. Mas la tierra

avaramente reclamó lo suyo,

lo que prestara un claro día, cuando

decir ceniza era decir belleza [...] (61)

En Los años y las sombras (1966), ${ }^{27}$ por ejemplo, la ceniza constituirá ya el acicate para reconstruir la memoria y el recuerdo, dos constantes cada vez más presentes en las postrimerías de la obra del autor que comparte con otros poetas de su misma edad, como con el José Hierro de Libro de las alucinaciones (1964), sin ir más lejos. El poema «Final» de ese libro de 1966 así nos lo confirma:

FINAL

«Es la hora: disuélvete, memoria.»

Una brizna de luz se precipita venas adentro, sangre adentro. Quítate de los ojos tanta vieja historia.

Quítate de la frente tanta escoria, tanto polvo de ayer, tanta maldita sed de un agua pasada y ya marchita en la rosa girante de la noria.

Es la hora de todos los olvidos.

Disuélvete, memoria, sueño, muerte, y gane la materia el lado izquierdo.

Los años y las sombras ya vividos solo ceniza pueden devolverte.

mas no sabrás vivir sin su recuerdo. (41)

El ejercicio de memoria es, por su parte, la consecuencia necesaria de esa traslación de la percepción del tiempo desde lo exterior hacia lo interior, una región del pensamiento donde ambas vertientes se entrelazan en la consciencia del sujeto. Así se percibe en el poema «El intruso» de Meditación en Socar (1982), donde la amenaza de la desmemoria añade ya un componente de pesimismo a los versos:

[...] En tanto pasa, soy.

En tanto me desnuda

del que fui, va vistiéndome

de tiempo y soledad.

Tropiezo en mí — ¿con quién

tropiezo?-, piso estancias

vacías, corredores

— ¿quién vive aquí? —, descanso

\footnotetext{
${ }^{27}$ Se terminó de escribir en 1963.
} 
Enclaves. Revista de Literatura, Música y Artes Escénicas, n.o 1, 2021, pp. 173-195. e-ISSN 2792-7350

María Eugenia Álava Carrascal, «Tiempo de ceniza (1961) de Carlos Murciano: entre el compromiso y la renovación del lenguaje en un poeta de Arcos de la Frontera», https://dx.doi.org/10.12795/enclaves.2021.i01.12

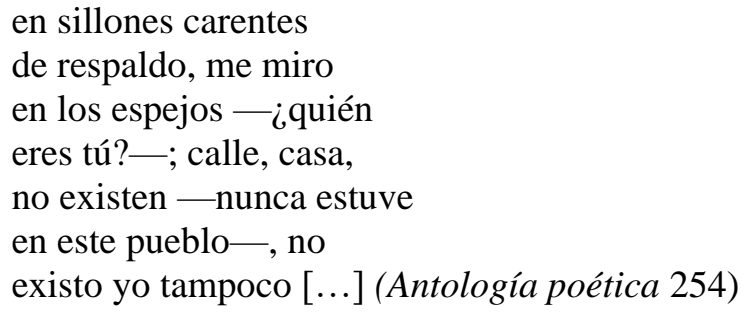

En Más allá de la soledad (1984), Concha Lagos haría un ejercicio muy similar, donde se podía percibir también la amenaza del olvido. Y Carlos Murciano le escribía una postal el 30 de abril de 1984 indicándole a su amiga sus impresiones sobre el libro. Abría esa misiva con una frase muy en la línea del pesimismo que ya podíamos ver en los versos anteriores: «del más hondo silencio se ha poblado todo» (Carlos Murciano apud. Lagos). Y, más adelante, le escribía: «más allá de la soledad, o más acá de la pena, lo cierto es que tus poemas confortan y acompañan» (Carlos Murciano apud. Lagos). Y es que ese sentimiento de soledad sería el culmen de la evolución de la concepción del tiempo en Murciano. Muy en consonancia con el devenir lógico de su propia vida, por otro lado, la revisión de la experiencia vivida, como conciencia, ya desde la entrada en la madurez, desembocaría lógicamente en un cierto sentimiento de nostalgia por el tiempo pasado hacia la década los ochenta, tal y como se percibía también en los versos citados de Meditación en Socar (1982).

Hemos planteado entonces que ya en el libro de 1961 el hombre se empieza a entender a sí mismo como experiencia vivida, en tanto que transcurrida, ${ }^{28}$ y como protagonista innegable de una historia que le es fundamentalmente propia. En ese punto se orquesta el cambio de perspectiva con respecto de la poesía social, meramente realista, y de vocación historicista. Y, en ese sentido, Carlos Murciano estaría en ese punto ya muy cercano a los planteamientos de algunos poetas como José Ángel Valente o el ya mencionado Claudio Rodríguez en sus respectivas poéticas, incluidas en la antología Poesía última (1963) de Francisco Ribes, que significó una transición coherente entre la poética del realismo comprometido y la de los nuevos novísimos, demostrando que la poesía de algunos autores estaba anclada en la reflexión interior de la experiencia, en el creciente individualismo entendido a varios niveles. Antonio Gamoneda es un ejemplo perfecto de esa evolución, tal y como lo señala Luis Miguel García Jambrina en su trabajo de 2009 La otra generación poética de los 50. Ello, por su parte, podía entenderse además como el último resquicio de la diatriba poética comunicación-conocimiento que habría comenzado en las líneas de fuego de la revista Laye en 1953, cuando apareció el artículo de Carlos Barral en el número 23 de la revista, titulado «Poesía no es comunicación», como respuesta al libro de Carlos Bousoño de 1952, Teoría de la expresión poética (Lanz, Las palabras gastadas... 18).

En suma, podríamos decir que la poesía de Murciano es esencialmente meditativa, tal y como José Olivio Jiménez definió la obra de los poetas que él consideraba pertenecientes a esa «generación del 60» que él mismo definió en 1972 (Lanz, Las

\footnotetext{
${ }^{28}$ Todos los poetas de los años centrales del siglo y de esa generación transitoria de los sesenta estuvieron también fuertemente influidos por la fenomenología que llegaba desde Alemania de la mano de Edmund Husserl, así como por Ser y tiempo (1927; quinta edición de 1941) de Heidegger, que fue traducido al español por primera vez precisamente en 1951 en México.
} 
palabras gastadas... 49). ${ }^{29}$ Quizás los máximos exponentes de esta dimensión podrían considerarse después Los años y las sombras (1966) y el Libro de epitafios (1967), entre los cuales existen claras conexiones de mapas semánticos, fundamentalmente, a través de los motivos de la sombra, la muerte, real y simbólica, y el epitafio. En Tiempo de ceniza, por su parte, ese componente meditativo se refleja fundamentalmente, además de en la concepción temporal de una intrahistoria como conciencia que señalábamos atrás, también en dos poemas de la primera sección del libro, «Nacer a muerte» $\mathrm{y}$ «Volver» respectivamente. El segundo, en particular, incorpora una reflexión donde la voz poética plantea al individuo encontrándose con uno mismo y ocurriendo una suerte de extrañamiento, de alucinación. Este tipo de reflexiones fueron habituales también en la poesía de algunos poetas tradicionalmente incluidos en el canon del realismo comprometido del medio siglo, precisamente como reflejo de ese creciente interés por lo individual frente a lo colectivo que, en aquellos autores que lo llevan al extremo, ocurre eventualmente la meditación. Traemos a colación algunos versos de «Volver» para ilustrarlo:
Volver es tropezarse con lo ido, con lo que se nos fue de las manos [...]
Volver es algo así como encontrarse con uno mismo y no reconocerse.
O sí: reconocerse mas no hablarse.
O sí: y hablarse, pero no entenderse. (37)

Y merecería la pena compararlos con unos versos de «Tiempo mío sin mí», del segundo apartado de Quinta del 42 (1952) de José Hierro, para ilustrar lo expuesto arriba. Con el ejemplo del poeta madrileño, lo temprano de esa modernidad sorprende. Además, en su caso, la voz poética recurre incluso al juego pragmático en el discurso lírico: «Yo creo en ti. Ciegamente / creo en ti. Te albergo. Guardo / tu recuerdo. Creo en ti / porque creo en mí [...]» (Hierro, Quinta del 42 72).

Ya acercándonos al final, el esteticismo es la última de las claves en que pensamos cuando abordamos Tiempo de ceniza y, por ende, también en el resto de la obra de Murciano, sobre todo a partir de este punto, pero que se entrecruza por todo su corpus, creando una suerte de poética que le sitúa ya sin remisión entre dos aguas: entre ese compromiso moral que se puede percibir dentro de todas las dimensiones subrayadas antes y esa aparente falta de dimensión engagé que pareció predominar en gran parte de la poesía española a partir de la segunda mitad del siglo XX. Algo que, en términos de los «otros novísimos» más comprometidos, los poetas leoneses de la ya mencionada revista Claraboya (1963-1968), podríamos denominar como «neodecadentismo» (Lanz, Las palabras gastadas... 198) para ejemplificar esa poética supuestamente compartida por la punta del iceberg que ejemplificaron después los Nueve novísimos de Castellet (1970).

Sin embargo, no se puede decir que los poemarios a partir de Tiempo de ceniza, sobre todo, traten los vanguardismos, ni los collages o juegos florales irónicos banales, ni el venecianismo al estilo de Guillermo Carnero o Pere Gimferrer, por ejemplo, en ningún sentido. Sí que hay rasgos de culturalismo en algunos de sus poemarios de los

\footnotetext{
${ }^{29}$ Invasión de la realidad (1962) de Carlos Bousoño es el título que Olivio Jiménez consideraba como inaugurador de esta tendencia en su trabajo de la Colección Ínsula de 1972.
} 
ochenta, como Historias de otra edad (1984) $)^{30}$ o Quizá mis lentos ojos (1986) —escrito el primero en los setenta-; pero ni siquiera es «neoesteticista» 0 «decadente», sino que simplemente está en la línea de una incipiente «suntuosidad expresiva» (Lanz, Nuevos y novísimos poetas... 20). Y también había algo de surrealismo ya desde sus poemarios de finales de los sesenta, donde algunos objetos tan simples como un reloj transcienden a su mera presencia física o las hormigas anuncian la metonímica llegada de la muerte, ${ }^{31}$ por ejemplo. Quizás los máximos exponentes de esta tendencia esteticista sean, cada uno en sentido parcialmente diferente y de menos a más, el conceptismo de los objetos de Este claro silencio (1970), la metáfora de la música como pulsión interna del poeta, incluso como silencio en algunos puntos de Clave (1972), ${ }^{32}$ y las alegorías de la muerte transmitidas a través de constantes rupturas versales y la novedad formal de Yerba y olvido (1977). Pero la reflexión sobre el propio lenguaje, de corte a veces preciosista, a veces conceptual, de metarreflexión en torno al propio verso y esencialmente simbólica que se consigue principalmente desde Tiempo de ceniza está llamada a asistir a esa dimensión meditativa de su poesía que venimos reclamando.

Volviendo entonces a centrarnos en el análisis de ese poemario, se podría decir que el compromiso ha ido cambiando de lugar, simplemente. Desde luego, en ningún sentido puede decirse que el compromiso desaparezca, como Manuel Urbano se encargaba de subrayar en el prólogo de Andalucía en el testimonio de sus poetas (1976), pero se orienta paulatinamente hacia uno mismo, en relación con esa ya mencionada intrahistoria y esa dimensión meditativa de la conciencia individual que se inscribe en la anterior diatriba comunicación-conocimiento, situándose en favor del segundo elemento del binomio. Y aunque el poeta nunca deja el contenido en un segundo plano, podemos percibir un claro interés por el cómo frente al qué en algunos puntos, precisamente como consecuencia directa de ese cambio de rumbo en las preocupaciones desde lo colectivo hacia lo individual. ${ }^{33}$ El tipo de compromiso será entonces el eje fundamental desde donde se orquesta el cambio, y la denuncia va trasladándose así también desde lo más crítico y beligerante hacia lo más puramente moral. Y todo ello motivado además por esa impronta andalucista que viene asistiendo a la retirada del realismo y la narratividad en favor del simbolismo de los versos. Porque es esa tendencia «simbolista» que destacaba Castellet

\footnotetext{
${ }^{30}$ De él diría Leopoldo de Luis en el número 720 de la revista Crítica en 1982 lo siguiente: «Consta de un bellísimo encadenamiento de mitológicas alusiones, posee una fuerte atracción simbólica y se convierte en uno de los mejores poemas no solo del volumen, sino de la obra de Murciano y aun de la poesía de nuestro tiempo» (Leopoldo de Luis apud. Murciano Maínez 256). Y una mayor ratio de culturalismo se puede encontrar sin duda en libros de finales de los noventa y del nuevo siglo, tales como Diminuto jardín como una araña (1998) y Cuaderno de Es Verger (2000), mezclado además con un punto de exotismo.

31 «Las hormigas», de Los años y las sombras (1965), fue precisamente el poema que Murciano seleccionó para la antología de poesía andaluza de 1961 de Cuadernos de Ágora, diferenciándose así voluntaria y explícitamente de la poética social-realista más llanamente narrativa del medio siglo. Y no se puede dejar de pensar tampoco en un simbolismo de corte neopopularista del Machado de Campos de Castilla, que se recuerda específicamente a través de las hormigas por su similitud con las aparecidas en «A un olmo seco». ${ }^{32}$ Editado también en La Isla de los Ratones, en el número 63 de «Poetas de hoy».

${ }^{33}$ De hecho, Manuel Urbano no incluía en su introducción de 1976 a Carlos Murciano dentro de la nómina de la llamada «Generación del cincuenta y tantos», bautizada así por Aquilino Duque para definir a los poetas andaluces más inclinados por la poesía social-realista durante los años cincuenta y primeros sesenta. Incluía, por su parte, a María de los Reyes Fuentes, Manuel García Viñó, Pío Gómez Nisa, Manuel Mantero, José María Requena, Julia Uceda y el propio Aquilino Duque, y les orientaba en torno a una poética más o menos común motivada por «una línea [poética] testimonial y directa» (23). Cierto es que aquellos se orientaron fundamentalmente en torno a un núcleo sevillano y, en eso, Murciano quedaba fuera.
} 
como parte de su nómina de novísimos en 1970 (Lanz, Nuevos y novísimos poetas... 40) precisamente la que más destaca en el poemario.

Partiendo de la concreción de los títulos de los poemas del libro, por ejemplo, estos son elementos que se convierten en símbolos-metáfora que concretizan el poema en torno a una idea inicial y después se mantienen a lo largo de otros versos convertidos en conceptos. En la primera sección del libro ello ocurre con «La araña», «El muro», «El tren», ${ }^{34}$ «El reloj» e incluso «El estudiante». Y llegará al cénit con «Todo», hacia el final de esa primera sección:

\section{TODO}

Todo lo que es ceniza a olvido suena y todo lo que es tiempo suena a huida. Ceniza. Tiempo. Arena por la vena. Muerte por la ancha vena de la vida. (39)

Esa tendencia se heredaría después en Del tiempo y soledad (1978), ${ }^{35}$ con una clarísima voluntad meditativa en ese laconismo ya en ese segundo caso, cuyo origen podríamos identificar en el poema «Donde el poeta empieza a ver claro» de Tiempo de ceniza:

Claridad. Lo que fuera

ayer, desnudo yace.

El cuerpo se deshace.

Claridad. Persevera

el alma (desespera

el alma), se eterniza

lo que no fue. La tiza

de la memoria escribe:

Final. El tiempo vive

—iclaridad!— su ceniza. (26)

En otras ocasiones, los símbolos se acumulan para generar una tendencia preciosista en los versos que destilan ese clasicismo tradicionalmente andaluz que dulcifica las impresiones del poeta. El lenguaje se refina y se sumerge en el mundo de las correspondencias, generalmente relacionadas con el mundo de la naturaleza, para trasladar ideas y sentimientos, casi siempre centrados en emociones profundas sobre la experiencia en la tierra. Cierta herencia juanramoniana es evidente también y se constata, por ejemplo, en el paratexto en forma de versos de Olvidanzas, que acompaña a la primera página de la primera edición de Este claro silencio: ${ }^{36}$ «Creímos que todo estaba / roto, perdido, manchado... / - Pero, dentro, sonreía / lo verdadero, esperando» (Juan Ramón Jiménez apud. Murciano, Este claro silencio 10). El poeta se las ingenia para resignificar el simbolismo de Juan Ramón hacia un nuevo concepto, más contemporáneo, inspirado en el elemento del conocimiento que Carlos Barral reclamó en el número 23 de Laye. Ejemplos clarísimos del simbolismo más preciosista se encuentran en la tercera sección

\footnotetext{
${ }^{34}$ Un soneto en Sonetos de la otra casa (1996) llevará este símbolo, con el mismo título, al extremo de su conceptismo.

35 Se comenzó a escribir en 1973.

${ }^{36}$ El maestro participó además en la revista Alcaraván asiduamente.
} 
Enclaves. Revista de Literatura, Música y Artes Escénicas, n. o 1, 2021, pp. 173-195. e-ISSN 2792-7350

María Eugenia Álava Carrascal, «Tiempo de ceniza (1961) de Carlos Murciano:

de ese poemario de 1961, «País donde seremos», donde los títulos de los poemas mantienen el rasgo de la concreción conceptista, pero los símbolos se desarrollan a través de los versos, conformando un caleidoscopio emocional, a menudo de carácter premonitorio frente a un destino que se prevé perverso. Un buen ejemplo de esto último viene dado por los primeros y últimos versos del primer poema de la sección, titulado «Geografía»:

\author{
Muerte limita al Norte con el Río \\ que llaman — los que viven - de la vida, \\ al Este con los Montes de la Nada, \\ al Oeste con la Isla del Olvido \\ y al Sur con el Océano de Dios [...]. \\ Muerte es la negación de la pregunta, \\ Muerte es el gran país donde seremos \\ sencillamente cuando no seamos. (51)
}

Por otro lado, otro elemento claro de ese creciente interés por el refinamiento del lenguaje, tal y como lo definía Urbano en la introducción a su antología de poetas andaluces de 1976, es una línea poética «interior o contenida» (18) que aparece reflejada a través de oraciones sintácticas lacónicas que asisten a la generación de una métrica centrada más en la palabra que en el propio verso, y que por ende influyen en una suerte de detenimiento del ritmo del poema en la lectura. Ejemplo claro de lo anterior es el poema «El tren», donde el discurso lírico se entreteje incluso con un carácter conversacional en algunos puntos para traducir los tintes lacónicos del diálogo en un sentimiento de creciente angustia:

[...] Luego el humo, cansado, denso, arriba.

Subimos sin saber nuestro destino.

Va completo, más siempre hay quien nos cede su sitio: «Aquí termina mi camino»,

dice y nos alegramos que se quede.

«Billete, por favor»... Y lo enseñamos

como con miedo: simplemente la vida.

Lo taladran con fuerza. Preguntamos

si es de ida y vuelta. «No. Solo de ida» [...]. (Tiempo de ceniza 30)

Así que, finalmente, siguiendo la concepción de Juan José Lanz, que definía en 2011, en su ya muy citado trabajo de referencia para el periodo de lo que él denomina la «generación del 68», la poética de los heterogéneos novísimos en los siguientes términos: «La concepción del lenguaje como único elemento capaz de llevar a cabo una ordenación de la realidad en el texto poético, capaz de construir una realidad autónoma en el poema» (15); es precisamente así como podemos entender la preocupación por el lenguaje en Tiempo de ceniza, porque el libro se construye ya en mucha medida en torno al propio lenguaje, creando una realidad autónoma que cada vez dependerá menos de aquello que es extraliterario para trasladar el universo poético del autor en lo sucesivo. 
Enclaves. Revista de Literatura, Música y Artes Escénicas, n. ${ }^{\circ}$ 1, 2021, pp. 173-195. e-ISSN 2792-7350

María Eugenia Álava Carrascal, «Tiempo de ceniza (1961) de Carlos Murciano: entre el compromiso y la renovación del lenguaje en un poeta de Arcos de la Frontera», https://dx.doi.org/10.12795/enclaves.2021.i01.12

\section{9:nclaves}

Revista de Literatura, Música y Artes Escénicas

\section{Conclusión}

Tiempo de ceniza puede entenderse como el punto de inflexión en el corpus poético de Carlos Murciano. Supone un punto intermedio entre una poética más bien realista y comprometida, una poesía mayoritariamente narrativa también, y una segunda etapa más esteticista donde la preocupación por la concreción del lenguaje, en cierto detrimento del mensaje, prima. Pero más allá de categorizaciones en dos etapas diferenciadas, que no serían demasiado fecundas para los fines de este breve trabajo, en el libro pueden verse las claves fundamentales de toda la poesía de Murciano, que atraviesan toda su obra y se dan cita en ese libro publicado en 1961. Y después de revisar algunas de ellas, parece que podríamos inscribirle como un poeta de esa desdibujada «generación del sesenta» que, sin un elemento aglutinador clave de las poéticas predominantes en los en ella incluidos, y sin siquiera un consenso en sus edades u orígenes geográficos por los diferentes críticos que han acuñado el término, trató de identificarse con la evidente evolución entre los dos estilos líricos predominantes en la península que, aunque en líneas sinuosas, sin duda mostraron algunos poemarios en el devenir de las décadas del cincuenta y del setenta.

Un simbolismo de luz crepuscular, herencia de ese andalucismo que se puede considerar como un valor añadido a la obra de muchos poetas originarios del sur de España en el medio siglo, le facilitó esa transición hacia parámetros de mayor introspección, puramente meditativos, que fueron diluyendo el compromiso más crítico y beligerante hacia un moralismo centrado más bien en la propia experiencia vivida por el sujeto como protagonista de su propio destino en el mundo. Así, el poeta se inscribe también en las líneas evolutivas compartidas por casi todos los poetas del momento a lo largo y ancho de la península, pero motivado en particular por una impronta especialmente marcada por sus orígenes andaluces. Una evolución similar se puede ver en la obra de otros poetas andaluces como Rafael Morales, Luis Jiménez Martos o la propia Concha Lagos.

El libro de 1961 sirve así, por un lado, como orientación entre una suerte de gran antes y después en materia de temas y formas. Pero, por otro lado, representa las claves y constantes de un corpus poético en el que es fundamental entender un carácter extremadamente continuista. El libro es, en resumen: (1) andalucista y simbolista; (2) que alberga un compromiso que desemboca en un deber moral, ante todo, de uno y para uno mismo; (3) con una concepción del tiempo histórico que se torna en tiempo intrahistórico a medida que avanza el poemario; (4) de corte puramente meditativo; (5) y con un interés por la concreción del lenguaje poético en aras de alcanzar cierto esteticismo renovador. Y así es también, en general, toda la poesía de Carlos Murciano, el poeta en la periferia que no encajó en las nóminas principales establecidas en torno a los núcleos de las «dos capitales» españolas de los años centrales del siglo XX.

En la «Palabra previa», del ya muy citado volumen antológico de Plaza y Janés, Carlos Murciano escribió: "NNadie es el mismo nunca" reza un verso de esta antología. Y el tornado fluir del tiempo "te cambia el corazón, / te salpica los ojos de ceniza", aunque te los llene de claridades. Empero somos uno» (5). Podemos decir entonces, para concluir, que su poética fue así el reflejo de la sociedad española de la posguerra hacia un individualismo creciente y palpable a muchos niveles, pero siempre cada vez más libre y menos influido por el determinismo autárquico de la primera posguerra, que ya Carlos Bousoño trataba de subrayar en su introducción a la poesía reunida de Francisco Brines en 1971, cuando diferenciaba a los poetas «sociales» de los «críticos» (Bousoño, Poesía 
Enclaves. Revista de Literatura, Música y Artes Escénicas, n.o 1, 2021, pp. 173-195. e-ISSN 2792-7350

María Eugenia Álava Carrascal, «Tiempo de ceniza (1961) de Carlos Murciano: entre el compromiso y la renovación del lenguaje en un poeta de Arcos de la Frontera», https://dx.doi.org/10.12795/enclaves.2021.i01.12

postcontemporánea... 48), y que, hoy en día, sin ir más lejos se hace más palpable que nunca.

\section{Agradecimientos y financiación}

Este trabajo se ha realizado dentro del Proyecto con ref. PID2019-107687GB-100 del MINECO.

\section{Referencias}

Arce, Manuel. Los papeles de una vida recobrada. Cantabria: Valnera, 2010.

Bousoño, Carlos. Poesía postcontemporánea. Cuatro estudios y una introducción. Madrid: Júcar, 1984.

Castellet, José María. Veinte años de poesía española (1939-1959). Barcelona: Seix Barral, 1960.

García Hortelano, Juan. El grupo poético de los años 50. (Una antología). Madrid: Taurus, 1978.

García Jambrina, Luis. La promoción poética de los 50. Madrid: Espasa-Calpe, 2007.

García Jambrina, Luis. La otra generación poética de los 50. Madrid: UNED, Varia, 2009.

García Tejera, María del Carmen y José Antonio Hernández Guerrero (Eds.). Poetas andaluces de los años cincuenta. Estudio y antología. Sevilla: Fundación José Manuel Lara, Col. Vandalia Maior n. ${ }^{\circ}$ 5, 2003.

García Posada, Miguel. 40 años de poesía española. Antología (1939-1979). Madrid: Cincel, 1979.

Guzmán Simón, Fernando. La poesía andaluza de la Transición (1966-1982): revistas y antologías. Vol. 3. Tesis doctoral. Universidad de Sevilla, 2008.

Hernández Guerrero, José Antonio. "Datos para la Historia de las Letras Gaditanas (19301960)", Gades, n. ${ }^{\circ}$ 4, 1979. Recuperado de http://www.cervantesvirtual.com/obravisor/datos-para-la-historia-de-las-letras-gaditanas-1930-1960/html/

Hierro, José. Quinta del 42. San Sebastián de los Reyes: Universidad Popular, 1991.

Lagos, Concha. "Postal de Carlos Murciano. 30-04-84" en Archivo de Concha Lagos, sig. Arch.CLagos/3/32BIS. Madrid: Biblioteca Nacional de España.

Lanz, Juan José. Nuevos y novísimos poetas en la estela del 68. Sevilla: Renacimiento, 2011.

Lanz, Juan José. Las palabras gastadas: poesía y poetas del medio siglo. Sevilla: Renacimiento, 2014.

Lanz, Juan José y Natalia Vara Ferrero (Eds.). La poesía como documento histórico. Poesía e ideología en la España contemporánea. Sevilla: Renacimiento, 2018.

López Azorín, Manuel. "Carlos Murciano en Tertulias de Autor” en Canal Norte TV (11 de octubre de 1966). Vídeo accesible en https://www.youtube.com/watch?v=R6AatojWut4

Machado, Antonio. La guerra. Madrid: Espasa-Calpe, 1937.

Murciano, Carlos. Tiempo de ceniza. Santander: La Isla de los Ratones, 1961.

Murciano, Carlos. Los años y las sombras. Gandía: Ayto. de Gandía, 1966.

Murciano, Carlos. El mar. Gran Canaria: Las Palmas, 1968.

Murciano, Carlos. Este claro silencio. Madrid: Ediciones Cultura Hispánica, 1970. 
Enclaves. Revista de Literatura, Música y Artes Escénicas, n.o 1, 2021, pp. 173-195. e-ISSN 2792-7350

María Eugenia Álava Carrascal, «Tiempo de ceniza (1961) de Carlos Murciano: entre el compromiso y la renovación del lenguaje en un poeta de Arcos de la Frontera», https://dx.doi.org/10.12795/enclaves.2021.i01.12

Murciano, Carlos. Arcos de la Frontera. Madrid: Everest, 1982.

Murciano, Carlos. Antología poética (1950-1988). Barcelona: Plaza y Janés, 1989.

Murciano Maínez, Jorge F. Tipologías del amor, del tiempo y de la muerte en la poesía de Carlos Murciano (1970 -1983). Tesis doctoral. Universidad Autónoma de Madrid, 2003.

Pérez Parejo, Ramón. Metapoesía y crítica del lenguaje. (De la generación del 50 a los novísimos). Cáceres: Universidad de Extremadura, 2002.

Prieto de Paula, Ángel Luis. Poetas españoles de los cincuenta. Salamanca: Ambos Mundos, 2002.

Urbano, Manuel. Andalucía en el testimonio de sus poetas. Madrid: Akal, 1976. 